\title{
Ambiência em Centro de Saúde Escola no Butantã, São Paulo: estudo comparativo sobre a percepção de conforto em 2010 e 2012 por usuários maduros.
}

\author{
Ambience in the School Health Center in Butantã, São Paulo: a comparative study \\ on the perception of comfort in 2010 and 2012 by mature users.
}

\author{
Suzanne Maísa Alves ${ }^{34}$ \\ Maria Luisa Trindade Bestetti ${ }^{35}$
}

Artigo recebido para publicação em Jan./2014 e aceito para publicação em Jul./2014.

\begin{abstract}
RESUMO
O estudo da ambiência avalia os impactos de aspectos extrínsecos ao Homem na sua qualidade de vida. O objetivo da pesquisa no Centro de Saúde Escola Prof. Samuel Barnsley Pessoa, em São Paulo, foi a identificação das características físicas no atendimento aos usuários maduros a partir da reforma nas instalações, analisando mudanças na percepção de conforto e bem-estar. Dados coletados através de entrevista semiestruturada, consulta a documentos, observação de rotinas em diferentes períodos, registro fotográfico e anotação de relatos. A análise considerou a escala de faces utilizada para qualificar as respostas, gerando resultados quantitativos. Concluiu-se que é significativa a percepção de maior conforto, com sentimento de valorização e menor desgaste após a reforma. A comparação dos resultados poderá gerar iniciativas para ajustar necessidades que tenham sido percebidas após o período mais crítico de obras.
\end{abstract}

Palavras-chave: Ambiência. Idosos. Gerontologia. Conforto. Bem-estar.

\section{ABSTRACT}

The ambience study evaluates the impacts of extrinsic aspects to human being on quality of life. The objective of the research at the School Health Center Prof. Samuel Barnsley Pessoa, in São Paulo, was the identification from the physical features of the service for mature users up to the rebuilt space, analyzing changes in the perception of comfort and wellness. Data collected through semi-structured interviews, documents consultation, observation of routines in different periods, photographic record and annotation of reports. The analysis examined the facial scale used to classify the responses, generating quantitative results. It was concluded that the perception is significantly greater comfort with feelings of appreciation and less wear after rebuilt. The comparison of the results can generate initiatives to fit needs that were perceived after the most critical period of works.

Keywords: Ambience. Elderly. Gerontology. Comfort. Wellness.

${ }^{34}$ Graduanda em Gerontologia na Escola de Artes, Ciências e Humanidades da Universidade de São Paulo (EACH USP), bolsista do Programa de Tutoria Científica no período de realização da pesquisa no Centro de Saúde Escola no Butantã e bolsista do Núcleo de Pesquisa Novas Arquiteturas Pedagógicas (NP NAP). E-mail: suzanne.alves@usp.br.

${ }^{35}$ Graduação em Arquitetura pela Universidade Federal do Rio Grande do Sul (FA-URGS), mestrado e doutorado em Arquitetura no Programa de Pós-Graduação em Estruturas Ambientais Urbanas da Faculdade de Arquitetura e Urbanismo pela Universidade de São Paulo (FAUUSP). Professora doutora na Escola de Artes, Ciências e Humanidades da Universidade de São Paulo (EACH USP) e pesquisadora do Núcleo de Pesquisa Novas Arquiteturas Pedagógicas (NP NAP). E-mail: maria.luisa@usp.br. 


\section{INTRODUÇÃO}

O tema da Ambiência é extremamente relevante considerando a necessidade de que se estudem aspectos extrínsecos ao idoso e como eles influenciam nos serviços de atenção, especialmente naqueles cujo objetivo primordial é a saúde física, mas que as melhores condições de atendimento possam ampliar os resultados e gerar mais qualidade no encontro entre os sujeitos. A saúde do idoso remete a ações voltadas para a análise global do contexto biológico, psicológico, social e cultural desses indivíduos, visando à qualidade de vida, definida pelo Grupo de Qualidade de Vida da divisão de Saúde Mental da Organização Mundial de Saúde (OMS) como sendo a "percepção do indivíduo de sua posição na vida, no contexto da cultura e sistemas de valores nos quais ele vive e em relação aos seus objetivos, expectativas, padrões e preocupações" (Fleck, 1998). Os serviços de atenção ao idoso, em especial as Unidades Básicas de Saúde com a estratégia Saúde da Família, oferecem um modelo centrado no usuário, inserido no contexto familiar e social. O processo de trabalho, que tem como finalidade a qualidade da atenção à saúde, busca promover o empoderamento tanto do usuário como da equipe de saúde, processo orientado pelo principio da integralidade e que requer como ferramentas a interdisciplinaridade, a intersetorialidade, a humanização dos serviços e a criação de vínculos entre todos os atores sociais envolvidos (RODRIGUES, ARAÚJO, 2013).

O objetivo da pesquisa no Centro de Saúde Escola Prof. Samuel Barnsley Pessoa, em São Paulo, foi o de identificar as características físicas no atendimento aos usuários maduros a partir da reforma nas instalações, analisando mudanças na percepção de conforto e bem-estar. Foi realizado levantamento de dados sobre as condições de acessibilidade, ergonomia e conforto ambiental. A comparação de dois momentos distintos, quando o projeto estava para ser implantado e no final da sua execução, permitiu reconhecer que a valorização do espaço físico altera a sensação de prazer, mesmo com a obra inacabada. Como metodologia proposta para esse projeto, os procedimentos para a realização de pesquisa qualitativa baseiam-se na coleta de dados relativos às condições de ambiência, através de observação da rotina de atendimento, com registro fotográfico e anotação de relatos, assim como aplicação de uma entrevista semiestruturada aos idosos atendidos, com perguntas relativas à percepção ambiental. 
O levantamento de dados técnicos sobre as condições de acessibilidade, ergonomia e conforto ambiental no equipamento estudado possibilita o confronto com as normas que os regulamenta, assim como o levantamento de exemplos registrados podem apresentar bons indicativos de ambiência, que possam ser comparados com o caso estudado. $O$ estudo da ambiência desejada para cada situação de espaço, em qualquer escala, traz subsídios importantes para o entendimento das condições físicas e emocionais do bem-estar, e nisso considerase a inserção de estímulos positivos que aprimorem o relacionamento de todos os sujeitos. Podemos afirmar que a gerontologia ambiental analisa as condições de ambiência do espaço construído pelo Homem para sua utilização, determinando as condições de conforto e segurança necessárias para o seu bem-estar. Considera-se a percepção ambiental como a capacidade de interagir com o ambiente imediato através dos sentidos, já que o meio ambiente construído utiliza valores objetivos como forma, função, cor, textura, ventilação, temperatura, iluminação, sonoridade e simbologia. Cada um desses valores objetivos compõe o espaço dimensionado e funcional, resultando no espaço da arquitetura (OKAMOTO, 2002) e determinando o nível de bem-estar dos seus ocupantes.

\section{AMBIÊNCIA E ENVELHECIMENTO}

O Homem vive em ambientes construídos, abertos ou fechados, privados ou coletivos, e deles recebe estímulos que podem afetar seu conforto. Pode experimentar diferentes sensações quando esses estímulos provocam os limites do seu corpo e, consequentemente, interferem no seu comportamento. Cores, formas e proporções provocam reações psicodinâmicas, gerando sentimentos e podendo emocionar, positiva ou negativamente (BESTETTI, 2010). A bagagem cultural do indivíduo determinará o que lhe é agradável ou não, pois as escolhas dependem da história de cada um. Falar em ambiência envolve pensar no bem-estar individual, através do equilíbrio de elementos que compõem os espaços considerando percepção espacial e orientação, conforto e qualidade ambiental, acessibilidade e segurança, ergonomia e Desenho Universal. Pressupõe o espaço como cenário onde se realizam relações sociais, políticas e econômicas desempenhadas pelos diversos grupos sociais, sendo uma situação construída coletivamente e incluindo as diferentes culturas e valores, possibilitando o protagonismo e a participação. A relevância da ambiência para a arquitetura refere-se à atenção a ser dada aos 
aspectos extrínsecos ao Homem e como eles influenciam no seu envelhecimento, em busca da qualidade no encontro físico entre os membros da sociedade. É possível caracterizar e reconhecer elementos que funcionam como fortes coadjuvantes ao bem estar subjetivo dos sujeitos que participam de quaisquer espaços, sejam públicos ou privados, de atividade ou de recolhimento.

A longevidade cresce no mundo e já é estudada de modo multidisciplinar, considerando que todas as fases do ciclo de vida humana estão mudando e adaptando-se às condições ambientais de cidades mais complexas, meios de comunicação mais velozes e tecnologias que aperfeiçoam equipamentos miniaturizados, a partir do advento da nanotecnologia. A pesquisa pública elaborada pela Fundação Perseu Abramo em parceria com o SESC São Paulo em 2006 e publicada em 2007 indica que o envelhecimento da população é uma realidade e aponta seu crescimento de $8 \%$ para $16 \%$ nos próximos 25 anos. Essa situação tem sido motivo de preocupação para as organizações que tratam da questão dos idosos e para aqueles que se dedicam à formulação de políticas públicas no país. Percebese também uma drástica diminuição da fecundidade, já que um terço da população brasileira (35\%) não tem filhos, enquanto que entre os idosos apenas $6 \%$ não tiveram filhos (NERI et al., 2007). Tais fatores já são significativos quanto aos cuidadores originais, geralmente filhos, ausentes por opção dos pais ou porque estão muito ocupados com seus próprios compromissos individuais: isso afeta os programas arquitetônicos domésticos e cria a necessidade de novas estruturas para abrigo desse público, a partir das mudanças de desejos da sociedade.

O estudo da Gerontologia abrange o processo do envelhecimento e não somente a velhice, considerando a longevidade como consequência de boa qualidade de vida. O grupo World Health Organization Quality of Life (WHOQOL) criado em 1995 pela OMS, desenvolveu instrumentos de avaliação da qualidade de vida pressupondo que seja uma construção subjetiva através da percepção do indivíduo em questão, multidimensional e composta por elementos positivos, tais como a mobilidade, e negativos, tais como a dor (FLECK, 1998). Essa é uma noção eminentemente humana, referindo-se aos mais diversos campos da vida, seja familiar, amoroso, social e ambiental, ou até a própria estética existencial. Pressupõe a capacidade de efetuar uma síntese cultural de todos os elementos que determinada sociedade considera seu padrão de conforto e bem-estar estar (CACHIONI; FALCÃO, 2009). Refere-se à busca de lugares preferidos, possibilitando variados tipos de experiências restauradoras, que podem ocorrer tanto 
em ambientes naturais, quanto em ambientes construídos. O fato de se estar em um lugar favorito induz mudanças fisiológicas ao proporcionar alterações de humor no sentido positivo, equilibrar a capacidade de atenção e possibilitar maior contemplação dos próprios sentimentos (MACEDO et al., 2008).

O processo de trabalho do gerontólogo prevê uma atuação em equipe multiprofissional na qual, podemos afirmar, o arquiteto é um dos profissionais que, claramente, muito tem para contribuir, já que o trabalho como construtor de espaços deve atender às necessidades relativas à garantia do conforto e da segurança para jovens e adultos, mas também para os idosos e àqueles que os atendem. Vai-se além da composição técnica, simples e formal dos ambientes, passando a considerar as situações que são construídas em determinados espaços e em determinado tempo, vivenciadas por um grupo de pessoas com seus valores culturais e relações sociais. O decréscimo da capacidade física na velhice pode ser um elemento gerador da dependência, como resultado do desequilíbrio entre a experiência da limitação funcional, as demandas do ambiente e as expectativas pessoais para o desempenho nas atividades da vida diária (DIOGO, 2006).

O estudo da ambiência desejada para cada situação de espaço, em qualquer escala, traz subsídios importantes para o entendimento das condições físicas e emocionais do bem-estar, e nisso considera-se a inserção de estímulos positivos que aprimorem o relacionamento de todos os sujeitos. Podemos afirmar que a gerontologia ambiental analisa as condições de ambiência do espaço construído pelo Homem para sua utilização, determinando as condições de conforto e segurança necessárias para o seu bem-estar.

De acordo com Schmid (2005), a casa não pode se limitar a abrigo do corpo se as necessidades não se limitam ao físico. O ambiente construído é mais que um conjunto selecionado de variáveis e parâmetros sujeitos ao cartesianismo das normas e, para tornar-se arquitetura, deve tornar-se algo contínuo e complexo. É um meio efetivo de vida que acontece no plano físico, sentimental e intelectual. Assim sendo, um projeto arquitetônico deve ser elaborado ajustando-se todos os componentes como um sistema complexo e inter-relacionado. Além dos aspectos compositivos e programáticos, é preciso articular as condições ambientais, observando-se características tais como percepção espacial e orientação, conforto e qualidade ambiental, acessibilidade e segurança, ergonomia e Desenho Universal.

Considera-se a percepção ambiental como a capacidade de interagir com o ambiente imediato através dos sentidos, já que o meio ambiente construído utiliza 
valores objetivos como forma, função, cor, textura, ventilação, temperatura, iluminação, sonoridade e simbologia. Cada um desses valores objetivos compõe o espaço dimensionado e funcional, resultando no espaço da arquitetura (OKAMOTO, 2002) e determinando o nível de bem-estar dos seus ocupantes. É aceito o termo meio ambiente como sinônimo de ambiência, porém considerando-se que aí também está inserido o meio moral além do material. Desse modo, o caráter inclusivo passou a ser mais bem considerado à medida que esse conceito foi evoluindo, com vistas à humanização dos espaços coletivos.

\section{ELEMENTOS DA AMBIÊNCIA}

No programa denominado Humaniza SUS, a partir de 2004, criou-se um grupo especialmente voltado a discutir e difundir princípios relativos ao estudo da ambiência nos espaços de saúde. De acordo com a Cartilha de Ambiência (2006), elaborada pela Secretaria de Atenção à Saúde - Núcleo Técnico da Política Nacional de Humanização do Ministério da Saúde - devemos considerar que:

- O espaço visa à confortabilidade, valorizando elementos do ambiente que interagem com as pessoas e garantindo conforto aos usuários.

- O espaço possibilita a produção de subjetividades através do encontro de sujeitos por meio da ação e reflexão sobre os processos de trabalho.

- O espaço pode ser usado como ferramenta facilitadora do processo de trabalho, favorecendo a otimização de recursos e o atendimento humanizado, acolhedor e resolutivo.

A confortabilidade referida na Cartilha de Ambiência enfatiza os componentes que atuam como modificadores e qualificadores do espaço, estimulando a percepção ambiental. Quando utilizados com equilíbrio e harmonia, criam ambiências acolhedoras, propiciando contribuições significativas nos processos de produção (BRASIL, 2006). Destacam-se aqui aspectos relativos à morfologia, à cinestesia, à arte, à acessibilidade, à luz e à cor, aspectos mensuráveis, e à privacidade, à individualidade e aos valores culturais, elementos intangíveis, mas claramente percebidos quando incorporados ao espaço.

Os espaços qualificados denotam equilíbrio e segurança, a partir da harmonização dos diversos componentes que possibilitam seu uso, sejam eles superfícies, passagens, áreas mobiliadas ou elementos de informação ou 
contemplação. Buscam-se formas, dimensões e volumes que configuram e criam espaços, que podem ser mais ou menos agradáveis, mas sempre adequados para as pessoas. Essa morfologia deve traduzir a composição que proporcione maior bem estar possível, especialmente dentro dos limites do uso compartilhado dos espaços coletivos de permanência prolongada, transitória mais demorada ou apenas de passagem.

Além da geometria definida pela composição de formas, a percepção do espaço por meio dos movimentos, assim como das superfícies e texturas, permite traduções que também qualificam o espaço. A cinestesia é, portanto, um meio de organizar elementos de estímulo relativos à organização de fluxos e de permanência nos ambientes, visto que é definido no dicionário Aurélio (FERREIRA, 2004) como sendo a sensação que o indivíduo experimenta, conscientemente, de sua existência.

Conforto é a condição de bem-estar relativa às necessidades do indivíduo e sua inserção no ambiente imediato. Envolve não somente a eleição de critérios térmico, acústico, visual ou ainda químico, mas também o acréscimo de emoção e prazer, atribuindo-lhe um caráter holístico, já que o ambiente construído é um anteparo existencial, sendo abrigo para o corpo e para a alma (SCHMID, 2005). Conforto Ambiental refere-se à adequação dos diversos aspectos sensoriais que modificam a sensação de bem estar no espaço físico. O Homem enfrenta as adversidades ambientais através do desenvolvimento de capacidades que permitem adaptações no relacionamento com o ambiente físico. Define-se resiliência como a capacidade de recuperação e manutenção do comportamento adaptativo frente a ameaças e eventos estressantes, possibilitando níveis normais de desenvolvimento (MAIA: FERREIRA, 2009). Analisam-se temperatura, ventilação e luminosidade, aspectos que alteram condições de habitabilidade, especialmente na questão física e na capacidade produtiva dos usuários.

Ergonomia é uma ciência aplicada que se ocupa do planejamento de tarefas, operações, ambientes de trabalho, equipamentos e máquinas adequados às capacidades, às limitações e aos desejos das pessoas, com vistas ao aperfeiçoamento do seu desempenho, e à redução de perdas e desconfortos resultantes de acidentes, danos e doenças (VITTA, 2006). Qualquer indivíduo pode ter restrições no desempenho de uma atividade em função de deficiência, idade avançada, condições socioculturais ou pelo desenho do ambiente. Restrição, termo utilizado pela Organização Mundial da Saúde no International Classification of Functioning, Disability and Health, de 2001, indica o grau de dificuldade que esse 
indivíduo possui para realizar alguma atividade. Cabe à ergonomia transformar positivamente as condições de trabalho para as pessoas no ambiente físico (mobiliário e equipamentos), sendo fundamentais os conhecimentos específicos do Desenho Universal. Os princípios básicos que norteiam esse conceito dizem respeito à adequação dos espaços a todas as pessoas, reduzindo esforços desnecessários e considerando a diminuição da capacidade motora, visual ou auditiva, através de soluções específicas. Boa sinalização, seja gráfica, tátil ou sonora, possibilita maior autonomia aos usuários de espaços coletivos, diminuindo riscos de desorientação. No caso de placas visuais ou táteis, é importante considerar posicionamento adequado, assim como uso de elementos gráficos facilmente decifráveis e com linguagem adequada às características culturais da população (ASSOCIAÇÃO BRASILEIRA DE NORMAS TÉCNICAS, 2004).

Recentemente, na década de 60, iniciaram-se estudos sobre as barreiras arquitetônicas e o aperfeiçoamento do desenho de espaços, considerando que a confortabilidade também pressupõe possibilitar amplo acesso dos usuários a todos os ambientes construídos, devidamente adequados às pessoas de variados padrões antropométricos, inclusive aquelas com necessidades especiais. A falta de alguns sentidos ou a mobilidade comprometida de pessoas com necessidades especiais têm nas especificações de acessibilidade a garantia de conforto e segurança, fator fundamental em projetos arquitetônicos para a construção de espaços visando ao bem estar, ao protagonismo e à participação. A adequação dos equipamentos complementares aos espaços tais como assentos, apoios e dispositivos de acesso, garante maior produtividade com menor esforço e evita danos à saúde.

Mas ambiência não é somente espaço físico, é também encontro entre os sujeitos, propiciado pela adequação das condições físicas do lugar e pelo exercício da humanização. Ao definir-se um layout adequado deve-se levar em conta o sentido proxêmico, relacionado à utilização do espaço territorial necessário ao Homem e que influencia seu relacionamento com os outros, seja esse espaço íntimo, pessoal, social ou público (OKAMOTO, 2002). O termo proxêmica foi cunhado pelo antropólogo Edward T. Hall, em 1963, para se referir ao fenômeno da proximidade humana que se manifesta, por exemplo, no encontro social entre indivíduos ou por distâncias socialmente aceitáveis. Hall (2005) fala das variantes que esta mesma dimensão social e espacial apresenta em diferentes espaços e culturas, onde essa mesma proximidade social varia. 
É importante considerar os valores culturais desses atores sociais, visto que estabelecem significados, positivos ou negativos, em relação aos estímulos do ambiente. $\mathrm{O}$ homem é um ser social que interage com um ambiente físico e um meio social, os quais podem favorecer ou não sua adaptação ao processo de envelhecimento (DIOGO, 2006). A bagagem cultural que vamos compondo junto aos grupos familiar e social ao qual pertencemos suscitará as emoções, positivas ou negativas, que podem interferir no conforto e na relação que estabelecemos com o ambiente construído. As percepções decorrentes das sensações vão além das simples reações aos estímulos externos, pois são acrescidas de outros estímulos internos que intervêm no comportamento, tais como fatores provenientes do tipo de educação, que dá ao homem a crença em seus valores pessoais, familiares, sociais e culturais (OKAMOTO, 2002).

A ideia de estar acolhido enfatiza o elemento protetor do conforto, caracterizando que todos buscam abrigos, o que ao longo das gerações teria auxiliado a sobrevivência de certos indivíduos e determinado sua vitória no processo de seleção natural (SCHMID, 2005). Uma ambiência que ofereça boas condições de uso do espaço possibilita que haja bom humor dos participantes, com tendência ao surgimento do riso, mas devemos considerar que enquanto um prédio bonito pode ocasionalmente exaltar um estado de espírito em ascensão, haverá momentos em que mesmo o local muito agradável não conseguirá expulsar sentimentos de tristeza ou misantropia (BOTTON, 2007).

Quando se pensa em projetar ambientes para o envelhecimento humano, essa abordagem apresenta-se particularmente pertinente, tendo em vista que esse processo modifica as relações do indivíduo com o seu ambiente. A compreensão dessas novas relações que os indivíduos passam a desenvolver com os seus ambientes à medida que envelhecem é, portanto, de fundamental importância para a tarefa de identificar as necessidades dos idosos em relação ao ambiente construído. Sabe-se que o processo de envelhecimento é um fenômeno bastante complexo e que ocorre de forma multidimensional. Toda e qualquer intervenção que vise aumentar a qualidade de vida dos idosos deve ter em vista essa complexidade, o que exige, necessariamente, uma visão interdisciplinar. Buscar os atributos do espaço físico e emocional através de projetos bem elaborados, em níveis de complexidade que vão desde peças do mobiliário até cidades planejadas, certamente contribuirá para o aperfeiçoamento da qualidade de vida que almejamos 
para um envelhecimento saudável, em busca de melhor bem-estar e equilíbrio ambiental.

\section{CARACTERIZAÇÃO DA PESQUISA}

O local da pesquisa foi escolhido por oferecer dados relevantes para comparação, em função de o Centro de Saúde Escola do Butantã trabalhar com o Programa de Saúde da Família e por estar em reforma, o que possibilitou diferentes situações com usuários de mesmo perfil, especialmente pessoas idosas, que compõem grupos em franco crescimento e que, portanto, determina um interesse ainda maior em conhecer como estão em atendimento hoje, mas também considerando melhores condições na oferta do serviço para aqueles que estão envelhecendo.

O Centro de Saúde Escola Prof. Samuel Barnsley Pessoa opera, desde 1977, por meio de uma parceria estabelecida entre a Universidade de São Paulo e a Secretaria de Estado da Saúde (SES), considerando o desenvolvimento de um projeto com características docente-assistenciais, assentado na atenção primária à saúde. Esse duplo vínculo possibilitou ao Centro de Saúde Escola aprofundar-se como centro formador de recursos humanos para a área da saúde, além de inspirar projetos de investigação em torno do desenvolvimento de tecnologias de atenção à saúde que possam permitir maior efetividade das ações no âmbito da atenção básica, em acordo com os princípios gerais que norteiam o Sistema Único de Saúde (SUS). Essa assistência viabiliza a proposição de ensino em serviço e pesquisa operacional e ratifica o compromisso ético com uma população pertencente à área geográfica do CSE, que depende desses serviços como alternativa viável para acesso ao SUS. Por trabalhar com o Programa de Saúde da Família e por estar em reforma, possibilitou diferentes situações com usuários de mesmo perfil, especialmente pessoas idosas, que compõem grupos em franco crescimento e que, portanto, determina um interesse ainda maior em conhecer como estão em atendimento hoje, mas também considerando melhores condições na oferta do serviço para aqueles que estão envelhecendo.

O CSE está localizado no Distrito Administrativo do Butantã e sua área se estende até o DA do Rio Pequeno, integrando o território da Coordenação de Saúde da Subprefeitura do Butantã. É bastante heterogênea, incluindo segmentos com 
população de alto poder aquisitivo (como a chamada City Butantã), vários núcleos de favela - São Remo, São Domingos, Imperatriz Dona Amélia, Jardim dos Pinheiros, etc. - e outros segmentos que compõem um espectro variado de condições socioeconômicas. Com base no Censo de 2000, verificou-se uma tendência a um perfil de maior concentração de idosos (11\%) em relação à média do município (9,3\%). O Censo de 2010 confirma esta proporção, justificando a grande afluência deste segmento etário (INSTITUTO BRASILEIRO DE GEOGRAFIA E ESTATÍSTICA, 2010).

Desde agosto de 2010 foi iniciada uma reforma das instalações, processo que já previa a melhoria nas áreas de espera através da renovação de mobiliário, iluminação e revestimentos. É importante o fato de que os consultórios igualmente receberam as adequações apontadas pela equipe médica e de enfermagem, assim como $o$ atendimento administrativo foi reestruturado para melhor acondicionamento das fichas com histórico dos usuários atendidos, possibilitando maior eficiência e produtividade. Cabe ressaltar que a renovação de elementos, assim como a atualização dos espaços de acordo com as novas demandas, possibilita melhores condições de trabalho, o que certamente se refletiu na satisfação de todos os sujeitos envolvidos no serviço.

\section{MÉTODOS E TÉCNICAS DA PESQUISA}

O questionário utilizado para coleta dos dados, como dito anteriormente, foi criado pela pesquisadora. Foi baseado em instrumentos desenvolvidos e/ou adaptados por outros pesquisadores: Lawton, com sua Avaliação das Atividades Instrumentais da Vida Diária; Perracini, Avaliação Multidimensional do Idoso Quadro 2.10, Avaliação Ambiental, adaptação do Home Environment Survey (HES) de Rodrigues et al., adaptado por Ferrer et al., com o propósito de identificar os impactos ambientais na segurança dos sujeitos em questão quanto aos motivos de quedas (PERRACINI; FLÓ, 2009); e o WHOQOL - abreviado, da OMS, versão em português, buscando aspectos referentes à qualidade de vida. Portanto, somente houve análise dos modelos existentes para que se organizasse o novo instrumento. Dito isso, é preciso traduzir os objetivos de cada questão e suas especificidades, desde já apontando a necessidade de aprimoramentos e ajustes, especialmente na linguagem utilizada. 
Foram definidos três grupos distintos de questões: o primeiro grupo de 15 perguntas considera a opinião do entrevistado sobre os recursos que o servem no Centro de Saúde, desde equipamentos e condições ambientais até quanto às pessoas com as quais têm contato direto. Desse modo é possível observar quais aspectos demonstram maior significado e se a percepção do entrevistado poderia estar focada para problemas relativamente fáceis de resolver, considerando elementos materiais do lugar ou o acolhimento pelos funcionários do atendimento. Aqui se destaca claramente a importância da ambiência como um estudo amplo e não apenas relacionado ao ambiente físico, mas também à humanização. Importante salientar a inserção de questões relativas à orientação, que pode ser potencializada por elementos gráficos ou táteis, além de informação oral. O segundo grupo envolve 5 perguntas relativas ao bem-estar físico, já que é preciso considerar o ambiente da espera como o momento em que a percepção sobre as acomodações se torna mais evidente, até mesmo pela situação emocional e/ou orgânica em que o entrevistado possa se encontrar. A complexidade dessa soma de informações só poderia ser auferida a partir de um questionário mais meticuloso, mas este se propõe a verificar informações espontâneas como meio de buscar quais questões possam ser mais significativas nesta análise do conjunto de elementos existentes nos locais pesquisados. O terceiro e último grupo, através de 10 questões, provoca 0 entrevistado a opinar sobre o serviço oferecido, também considerando os recursos materiais e humanos disponíveis. Ele auto-avalia seus esforços e seu conforto, sempre considerando que sentir-se acolhido também se refere a conforto.

Optou-se por escala de faces por considerar a possibilidade de entrevistaremse pessoas com pouca ou nenhuma escolaridade, o que de fato ocorreu. A régua foi utilizada como referência ao modo como o entrevistado sentia sua própria emoção em relação à questão solicitada. Os questionários foram aplicados em 2010/2011 e 2012 com o auxílio das acadêmicas do Curso de Gerontologia da USP, Denise Martins e Suzanne Alves. Também foram feitos registros fotográficos em diversos ambientes do CSE, sendo que as imagens podem ser ainda mais significativas quando comparamos os resultados dos questionários nos distintos períodos, apontando dados relevantes que permitem analisar em que medida as intervenções no espaço foram percebidas. 


\section{DISCUSSÃO DOS DADOS}

Para melhor comparação entre os períodos e evitando repetições, passaremos a chamar o primeiro levantamento, feito em dezembro de 2010 e janeiro de 2011, de ANTES e o segundo levantamento, feito em setembro de 2012, de DEPOIS. Já no portão de entrada se percebe que ainda há ajustes finais a serem executados, visto o desgaste do portão ainda com a pintura anterior.

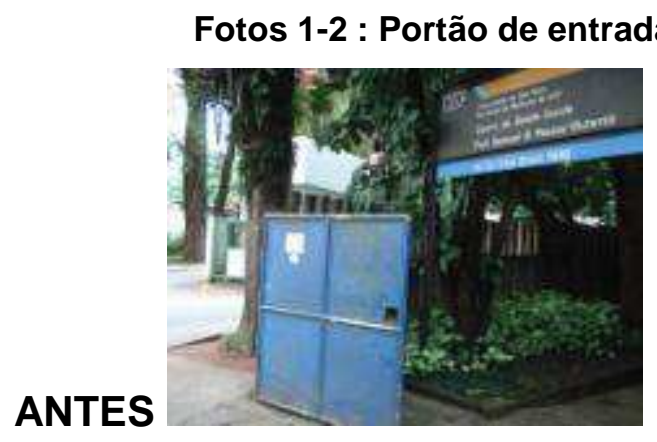

Foto 1
DEPOIS

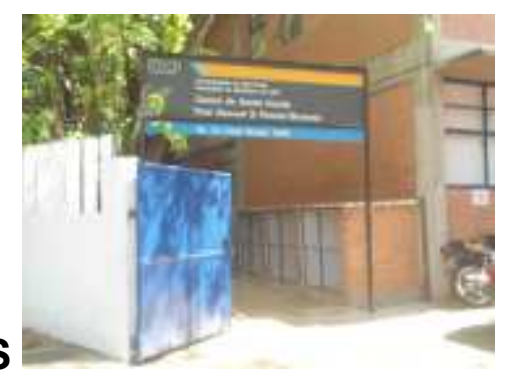

Foto 2

Quanto aos dados gerais, foram entrevistados 11 sujeitos na primeira fase e 13 na segunda, entre homens e mulheres. As idades variaram entre 61 e 84 anos na primeira fase, sendo que na segunda optou-se por incluir pessoas mais jovens, considerando a importância de considerar se as percepções apresentariam alguma mudança significativa, o que não ocorreu. Quanto à escolaridade, manteve-se a diversidade nos níveis de escolaridade encontrados, embora já não tenha sido encontrado qualquer sujeito sem escolaridade na segunda fase, inclusive incluindose um com curso superior completo.

Quanto aos resultados do questionário, é preciso considerar as reformas, que certamente criaram incômodos em determinadas fases da desmontagem e construção. Na ocasião a administração definiu uma setorização para minimizar os efeitos nocivos dos ruídos, da poeira e da movimentação atípica de materiais e pessoas, reservando tais interferências para áreas controladas e sem acesso do público. Hoje já encontramos áreas completas finalizadas, melhores em luminosidade e em pleno funcionamento, conforme demonstrado a seguir. 
Fotos 3-5: Corredor de acesso as salas de atendimento, antes durante e após a reforma.

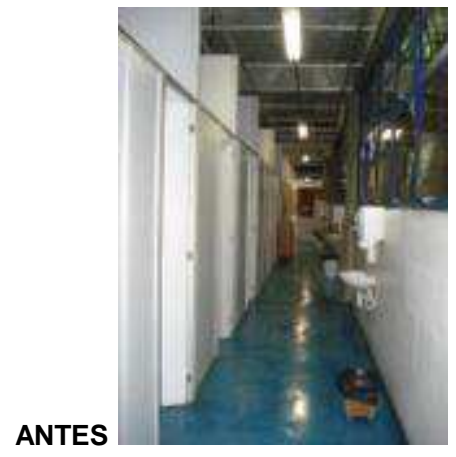

Foto 3

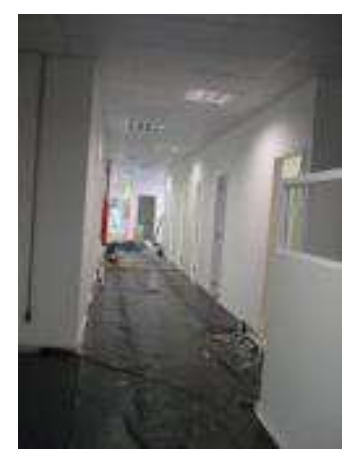

Foto 4

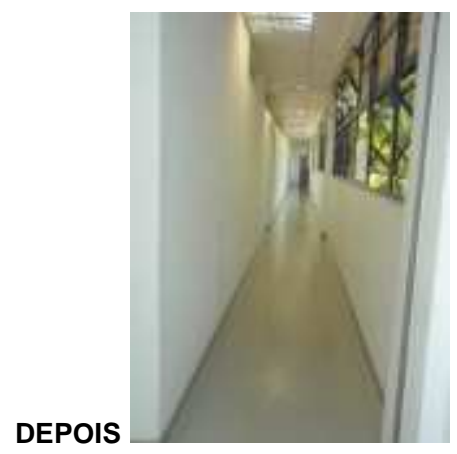

Foto 5

Percebem-se, portanto, que alguns resultados, tais como temperatura, iluminação, ventilação e poeira, demonstram terem sido afetados por esta diferença. Apesar dos transtornos da reforma na primeira fase, houve plena satisfação, levemente menor na segunda fase, mas ainda muito satisfatória. Interessante notar que a questão sobre o incômodo causado por ruídos apresentou resultados semelhantes antes e depois, com maior insatisfação na segunda fase, provavelmente ainda relacionado ao comportamento das pessoas. Quanto à iluminação houve aumento significativo de satisfação, sendo que aumentou a insatisfação com a ventilação atualmente. A poeira também incomoda um pouco mais agora, apesar de não haver qualquer manifestação negativa, talvez porque anteriormente o andamento da obra já justificasse essa situação. Quanto a placas de informação, na primeira fase houve um resultado mais satisfatório no geral, mesmo apresentando alguma restrição, e agora aparecem manifestações mais negativas e, nesse caso, certamente a incompletude do projeto executado é o causador dessa percepção. É preciso que haja uma programação mais clara e direta, porque a tentativa de comunicar graficamente muitos elementos acaba por criar desorientações que, certamente, acabam por interferir negativamente nos processos internos, seja por falta de compreensão e necessário atendimento personalizado, seja pela ansiedade que essas situações causam em pessoas menos esclarecidas ou com mais dificuldades de comunicação. 
Fotos 6-9: Placas de informação nos corredores de acesso aos pacientes.

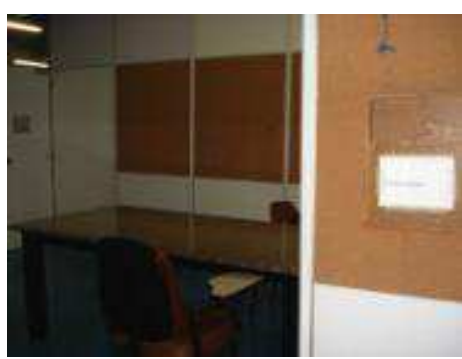

Foto 6

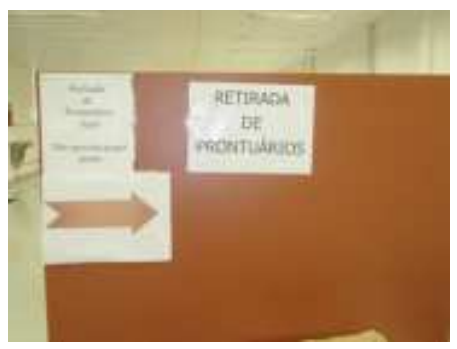

Foto 8

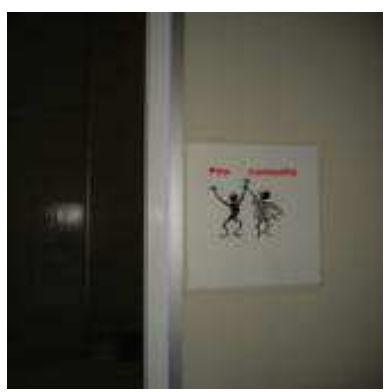

Foto 7

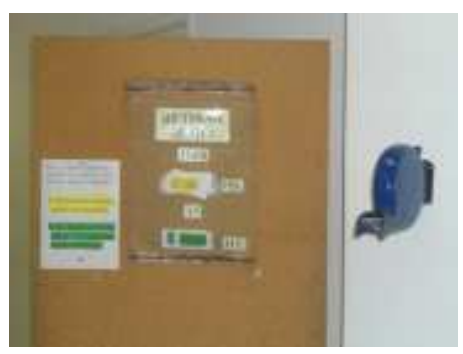

Foto 9

O balcão de atendimento, como dito no relatório anterior, é um elemento de grande importância para 0 acolhimento e, portanto, representa um item muito significativo nesta análise. Os balcões de atendimento apresentavam opiniões divididas na primeira fase, resultado que pode ter sido afetado pelo momento da reforma. Cabe destacar que as condições anteriormente existentes já demonstravam a necessidade de revisão, devido ao tempo de uso do mobiliário e à mudança de perfil do usuário, mas confirmam-se os indícios de que o bom atendimento já reduzia a percepção dessas deficiências. Apesar da indiscutível diferença tanto no layout pós reforma quanto na qualidade dos balcões e cadeiras de atendimento, os bancos de espera podem ter causado um sensível aumento de opiniões negativas, pouco significativas de acordo com a comparação entre os gráficos. 
Fotos 10-14: Balcão de atendimento modernizado, com cadeiras mais confortáveis.

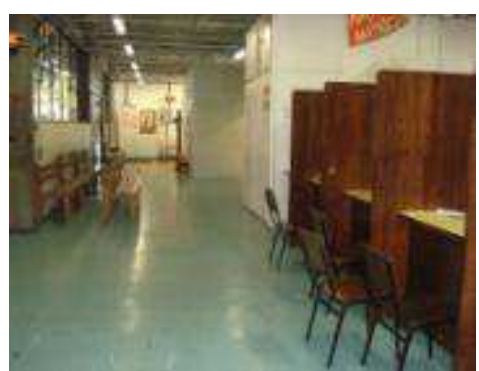

Foto 10

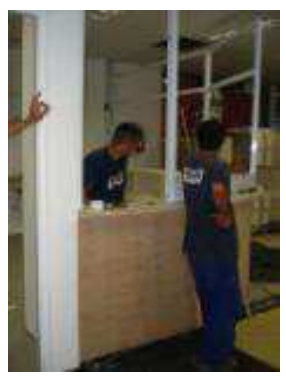

Foto 11

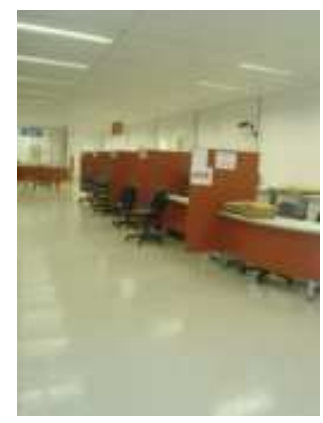

Foto 12

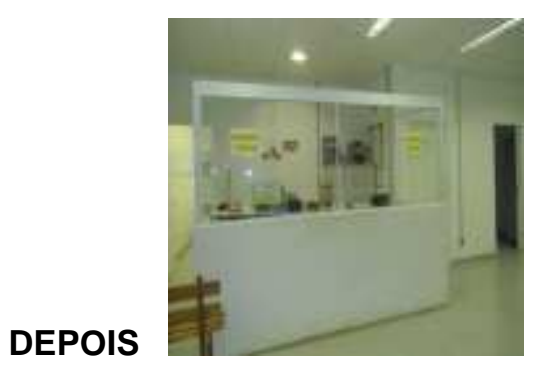

Foto 13

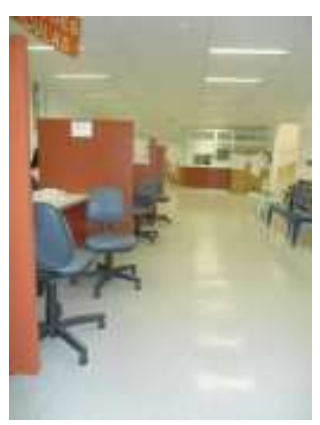

Foto 14

A questão sobre os bancos de espera, certamente o equipamento melhor percebido quando se verificam condições de conforto, obteve resultados negativos em ambas as fases de pesquisa, comprovando que sentar determina esforços que se agravam quando os assentos não têm proporções adequadas por estudos ergonômicos, especialmente quando a fragilidade do idoso potencializa esta percepção. O aumento de percepções negativas certamente se dá ao se comparar a melhoria nas condições gerais do ambiente, visto que os bancos anteriormente usados foram mantidos temporariamente e causa um contraste evidente com a qualidade do ambiente construído. Nem mesmo o uso de cores mais intensas, que poderiam evidenciar mudanças positivas, certamente não minimizaram o desconforto causado pelos assentos originais. 
Fotos 15-18: Bancos de espera com a modificação das cores.

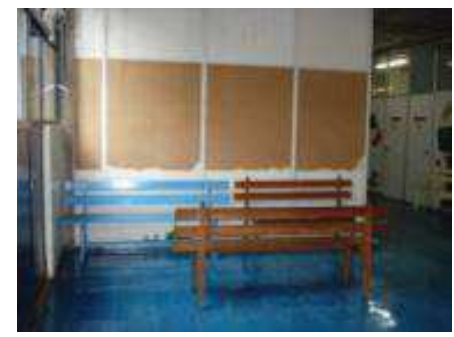

Foto 15

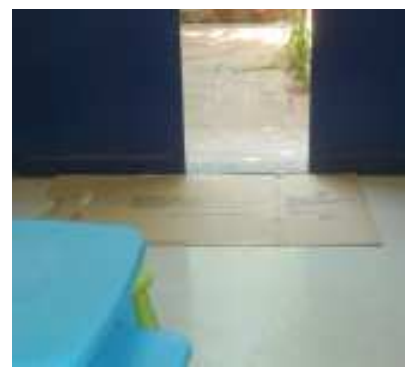

Foto 17

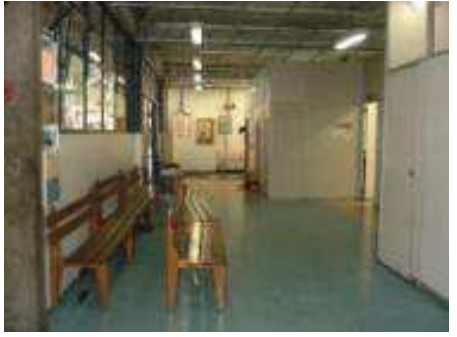

Foto 16

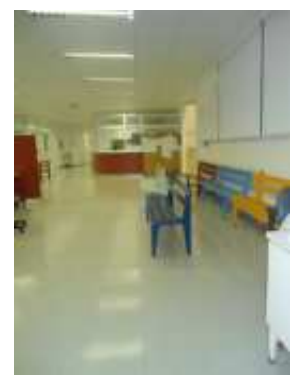

Foto 18

A pergunta sobre as condições de circulação envolve não somente o espaço disponível, mas a facilidade de alcançar os diversos pontos de atendimento, considerando desde a chegada, a espera, o atendimento propriamente dito e a saída. O layout do mobiliário pode ser um sinalizador de trajetos ou pode confundir, ocasionando conflitos de circulação, e é nessa premissa que se buscou um resultado. Em ambas as fases percebe-se que há respostas positivas, mesmo com alguma restrição, embora a insatisfação anterior certamente esteja relacionada aos arranjos provisórios estabelecidos em função da reforma, ainda com alguns elementos a serem ajustados. Há móveis sob a escada e outros avulsos, prevendose uma destinação mais adequada em breve.

A opinião sobre os consultórios apresentou alguma restrição na primeira fase, mas atualmente a aprovação é bastante significativa, como pode ser percebido pela comparação de imagens em três diferentes momentos. 
Fotos 19-21: Salas de consultas antes e após a reforma, com mobiliário novo.

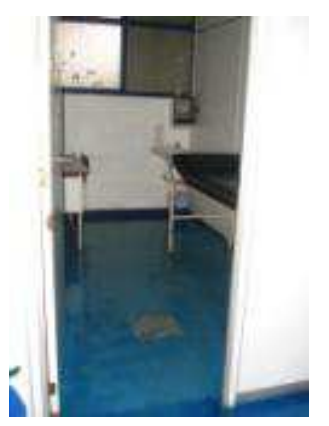

Foto 19: 06-03-2010:

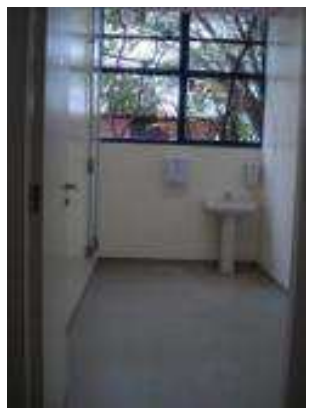

Foto 20: 16-12-2010

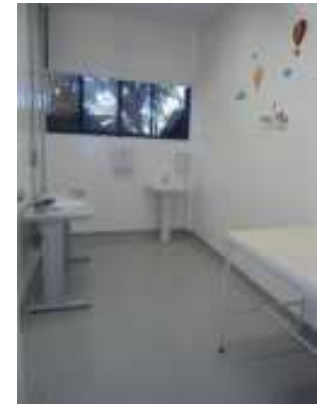

Foto 21: 29-09-2012

Já quanto à acessibilidade, fica claro que o atendimento no andar superior em função da reforma e sem sistema elevatório operante dificultava a mobilidade. Com a instalação de um elevador defronte à escada, onde funcionava a porta principal, o acesso a todos ficou garantido. Cabe salientar que dois aspectos devam ser observados: a falta de sinalização adequada ainda provoca alguma desorientação quanto ao uso do elevador, o que deve ser resolvido facilmente. Também quanto a esse espaço há mobiliário inútil acumulado em frente ao elevador, agravando esta situação, além de o piso estar incompleto no momento da coleta de informações desta segunda fase. Outro aspecto importante refere-se à espera provisória para a farmácia, organizada entre as duas portas na entrada principal. Além de diminuir o espaço de manobras, especialmente no uso de cadeiras de rodas, os bancos estão posicionados em frente à entrada, expondo as pessoas que esperam. Há muitos elementos complementares a esse ambiente que contribuem para uma percepção confusa sobre os acessos, conforme demonstrado nas fotos. 
Fotos 22-27: Reforma das escadas e a modificação da entrada com a introdução do elevador.

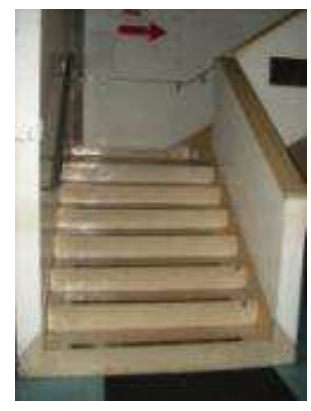

Foto 22

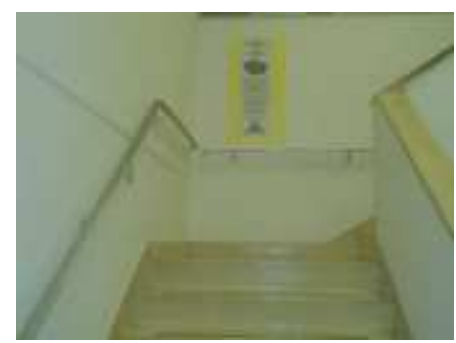

Foto 24

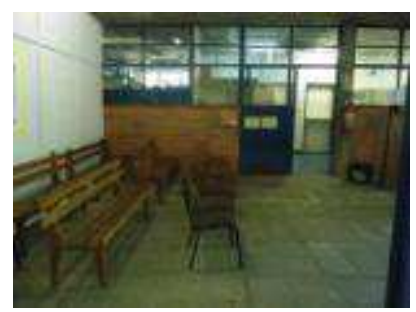

Foto 26
ANTES

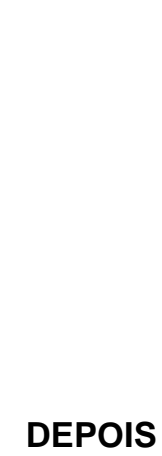

DEPOIS

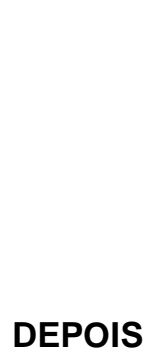

DEPOIS

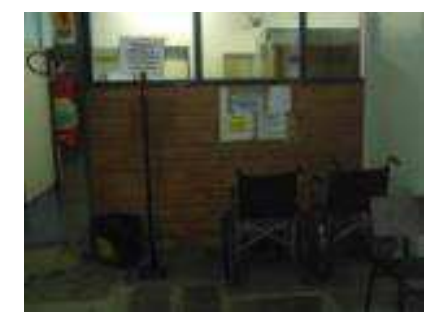

Foto 27

A questão sobre a qualidade na manutenção dos equipamentos ainda causa muitas dúvidas, pois envolve não somente elementos eletromecânicos, mas também os móveis, placas e sistemas de transição, tais como escadas, rampas e portas. Reitera-se a possibilidade de a pergunta não ser suficientemente clara para conclusões mais significativas. Portanto, mesmo de modo geral mantendo-se a percepção satisfatória, surgiu uma opinião enfaticamente negativa, apesar de todas as melhorias claramente percebidas a partir da execução da reforma. Destaca-se o desgaste das fitas antiderrapantes na escada e da rampa de acesso à farmácia, solução provisória que pode resultar em quedas. 
Fotos 28-31: Correção de alguns dispositivos que necessitam de manutenção frequente.

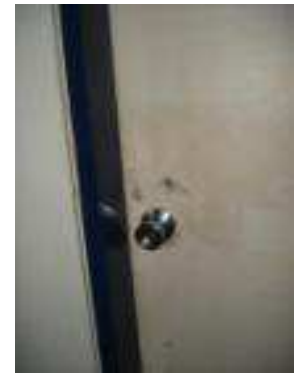

Foto 28

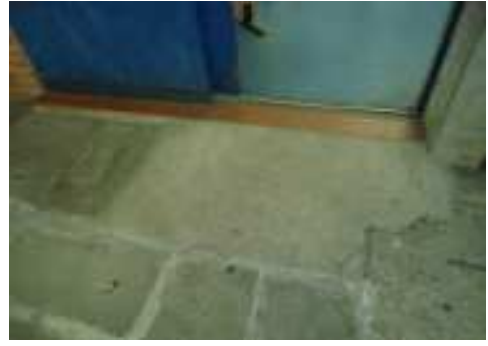

Foto 30

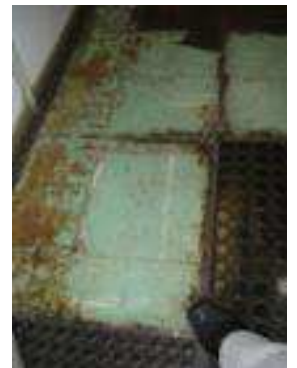

Foto 29

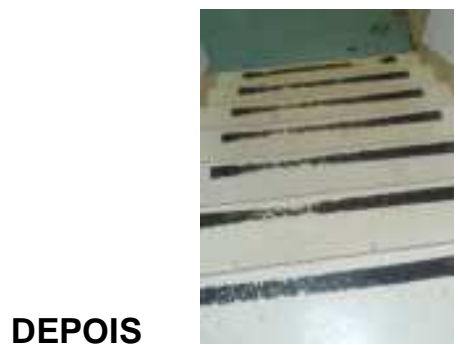

Foto 31

Os itens simpatia do pessoal de atendimento, relacionamento com outras pessoas no ambiente de espera e atendimento a sugestões e solicitações novamente podem ser comparados em conjunto, pois demonstram que o ambiente moral é positivo, seja pelo acolhimento da equipe em serviço, seja pela possibilidade de interação que os usuários encontram nos ambientes de espera. Como já registrado na análise de dados anterior, a ambiência deve ser ferramenta facilitadora da produção de subjetividades e dos processos de trabalho. A distribuição dos espaços e seus equipamentos devem ser necessariamente complementados por um atendimento humanizado, para que se alcancem resultados produtivos. Considerando um pequeno decréscimo na aprovação desses itens, mesmo com o mobiliário e a sinalização pouco adequados o resultado demonstra boa relação dos entrevistados com a equipe de trabalho, o que torna a espera menos penosa e passível de interações.

As cinco questões relativas às sensações dos entrevistados quanto ao seu conforto novamente serão analisadas de modo conjunto, pois se referem basicamente ao período de espera, sentados e autoavaliando seu bem-estar neste intervalo de tempo. Nas três primeiras perguntas, referentes à dor/desconforto nos braços, pernas e cabeça, as respostas neste novo levantamento demonstraram um 
decréscimo de satisfação, especialmente no item 2. Já no item 4 , referente a dor/desconforto nas costas, é bastante significativa a insatisfação, sem qualquer manifestação totalmente positiva. É preciso considerar que a escolaridade e o nível econômico afetam as percepções e, portanto, a possibilidade da inexistência de parâmetros de comparação com mobiliário mais adequado. Também vale lembrar que as mudanças positivas, tais como a modernização dos espaços e a melhoria de iluminação podem ter gerado maior percepção de que os bancos, que permaneceram, não acompanham a mesma qualidade nesta nova fase.

Fotos 32-33: Distribuição do espaço e dos equipamentos.

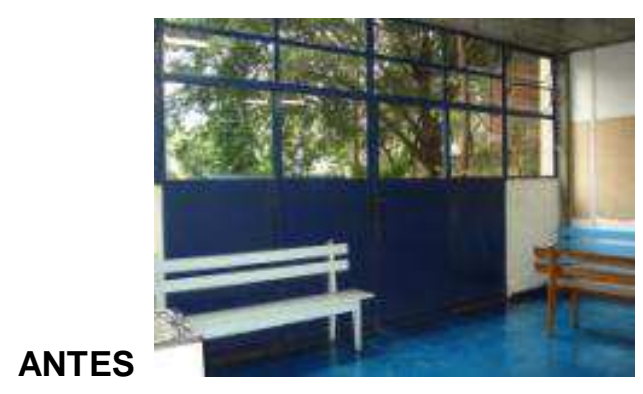

Foto 32

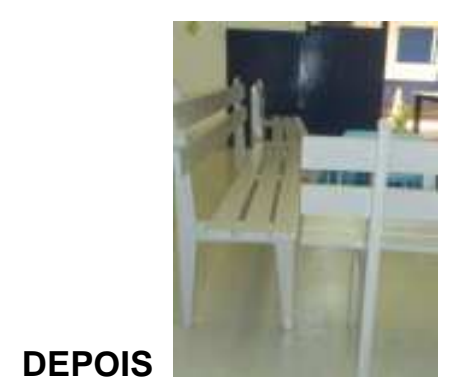

Foto 33

A questão sobre a dificuldade de circulação na espera também obteve resultados semelhantes, embora com decréscimo. Sugere-se uma reorganização do layout adotado, além de melhoria no sistema de alerta sobre a ordem de atendimento, o que causa desconforto e tende a criar situações de acúmulo e ansiedade.

As oito perguntas seguintes novamente solicitam a opinião de cada entrevistado sobre o que ele percebe nos ambientes de espera e atendimento, autoavaliando seu desempenho e sua relação com o serviço. Requer manifestações sobre seus esforços, mantendo-se a ênfase no físico, provavelmente considerando as distâncias a serem vencidas e o uso da escada, agora minimizado pela instalação do elevador. Também a posição dos bancos de espera acaba por gerar desconforto físico, em função da ansiedade ao manter a atenção para o sistema de chamadas, o que pode justificar manifestações menos positivas quanto ao esforço mental. 
Fotos 34-37: Grau de dificuldade/facilidade na circulação do ambiente de espera.

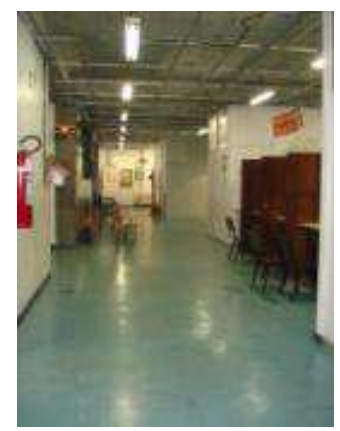

Foto 34

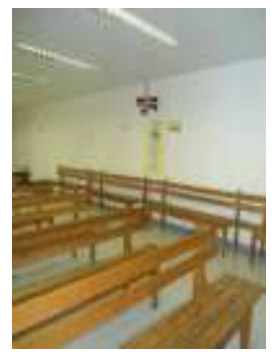

Foto 36
ANTES

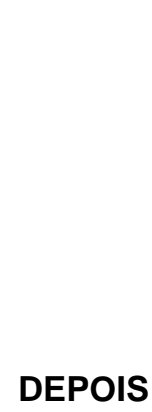

DEPOIS

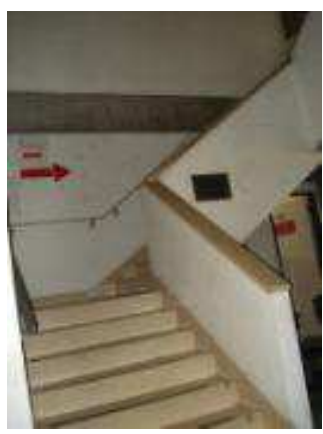

Foto 35

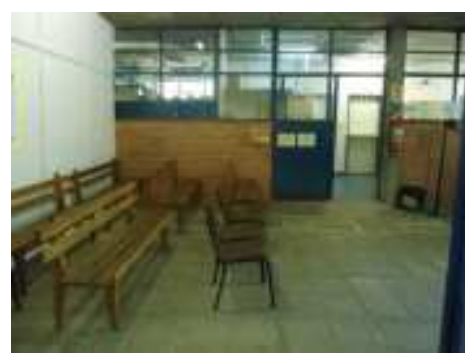

Foto 37

Os resultados quanto à monotonia na espera apresentaram um decréscimo significativo, mesmo mantendo a suposição de que toda espera causa tédio e que os diferentes níveis de ansiedade geraram respostas também diferentes. Podemos manter as sugestões apresentadas na análise da primeira fase: podemos lançar mão de recursos não somente visuais, tais como elementos decorativos ou aparelhos de TV, mas também sonoros, utilizando música ambiente. Exposições temporárias, assim como performances de teatro ou instrumentais, também poderiam ser recursos de humanização dos ambientes.

Fotos 38-39: Os espaços de espera contam com poucos elementos de distração.

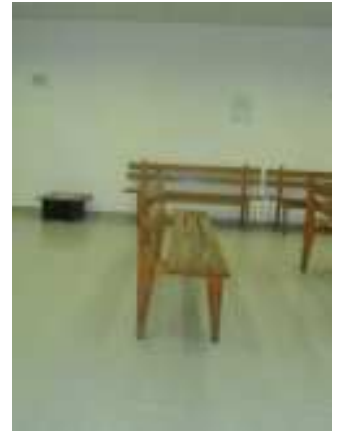

Foto 38
DEPOIS

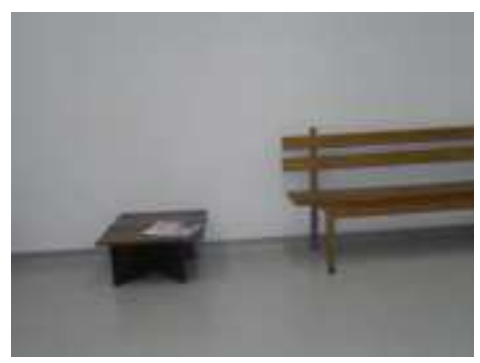

Foto 39 
Sobre o dinamismo do atendimento pode-se perceber que a avaliação tornouse menos positiva sobre o pessoal de serviço. Ao se perguntar sobre a diversificação das atividades, o que poderia confirmar sobre a monotonia do ambiente de espera, confirmam-se as percepções negativas e a necessidade de dispositivos que auxiliem nas interações entre profissionais e público atendido. Um aspecto importante sobre o bem-estar refere-se à presença de jardins, vistos através de algumas janelas que permitem apreciar a exuberante vegetação das áreas externas que contornam o edifício. Tais atributos podem minimizar o nervosismo decorrente da espera e melhorar a percepção sobre o atendimento. Neste momento os espaços ajardinados encontram-se prejudicados pelos impactos da obra ainda em finalização, o que se pode notar desde o jardim frontal até as áreas laterais, especialmente próximas da espera do atendimento na pediatria. Certamente a recuperação desses espaços e, até mesmo, uma reconfiguração, poderão criar ambiências mais agradáveis aos usuários e funcionários, considerando as experiências de prazer que ambientes naturais geralmente oferecem.

Fotos 40-41: Diminuição da vegetação devido aos impactos da obra.

ANTES

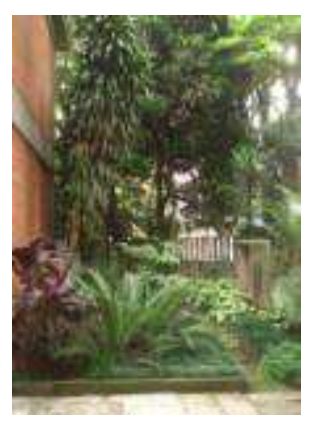

Foto 40

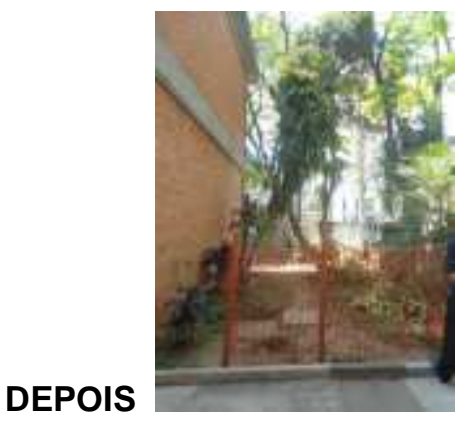

Foto 41

A dificuldade em responder a essas três questões (monotonia, dinamismo e diversidade) ainda indica a dificuldade em observar criticamente seu próprio bemestar no relacionamento com o serviço oferecido. Mesmo assim, quando perguntados sobre o quão se sentem valorizados no atendimento, manteve-se a resposta positiva.

Quanto à questão 7 , houve significativo aumento de satisfação, certamente pela implantação do elevador e pela troca do piso, mais claro, agregando maior segurança na deambulação, apesar do desgaste das faixas antiderrapantes na escada. No item 8 ficou evidente a percepção mais precisa das dificuldades com 
orientação, seja visual ou oral, visto não haver ainda um sistema de sinalização mais adequado.

As duas últimas questões solicitam opiniões diretas sobre autopercepção dos entrevistados quanto ao lugar, sendo que a questão 9 pergunta sobre seu "nervosismo" na espera em função do ambiente, na tentativa de separar o sentimento de tédio da relação com o uso do espaço físico. Houve um aumento da percepção negativa, mesmo com as melhorias decorrentes da reforma e, mais uma vez, é preciso considerar a possibilidade de que o atendimento esteja sendo percebido de modo diferente em função das mudanças físicas. Por fim, ao serem questionados sobre o conforto oferecido no Centro de Saúde, confirma-se essa hipótese, o que demonstra uma melhor compreensão sobre os elementos abordados no questionário. É necessário ainda considerar a baixa escolaridade como um indício para a dificuldade em compreender o conceito de conforto, o que pode justificar o resultado alcançado. A mudança do mobiliário, agora mais adequado, e da iluminação junto ao piso mais claro, aumenta o nível de exigência dos usuários, considerando-se aqui que esse fato pode tornar as pessoas assistidas mais comprometidas com o serviço oferecido, garantindo melhores resultados para atingir as metas desejadas.

Fotos 42-43: Novo uso do espaço físico, proporcionando distração antes do atendimento.

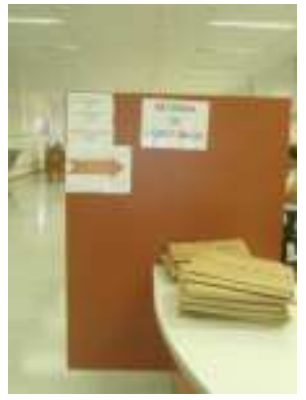

Foto 42

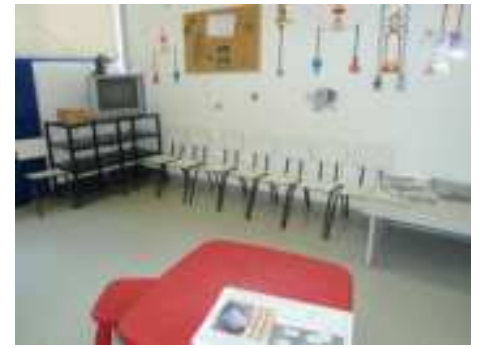

Foto 43

\section{CONSIDERAÇÕES FINAIS}

No levantamento anterior foi claramente percebido que 0 atendimento fora considerado muito bom, em vista das condições físicas do lugar. Com a reforma e melhoria de muitos aspectos extrínsecos, aumenta o nível de exigência das pessoas atendidas e a satisfação com o atendimento aparece menor, contrastando com a percepção anterior do acolhimento que gera as condições emocionais de 
permanência e ameniza os problemas do ambiente físico. Mesmo cientes de que faltam alguns elementos que finalizem a reforma pretendida, enfatizam-se as necessárias adequações que poderão melhorar as relações de trabalho no CSE. Os principais aspectos ainda se referem ao mobiliário e à sinalização, geralmente pouco considerados como elementos de conforto e já apontados na análise feita na primeira fase. Os bancos que ainda permanecem, apesar do uso de cores para torna-los melhor inseridos no conjunto, continuam proporcionando o mesmo desconforto e, portanto, contrastam com a qualidade das instalações. Também é importante pensar em layouts mais compatíveis com a reunião de grupos de pessoas que esperam, além de proporcionar mais elementos de distração. Quanto à sinalização, foi mantida a análise anterior, onde a desorientação foi apontada como um fator de desgaste por gerar insegurança e contrariedade. $O$ tempo despendido pelo pessoal em serviço, parando para dar informações, deve ser evitado, enfatizando melhor a posição das equipes de recepção e implantando um sistema gráfico e tátil que permita ao usuário maior protagonismo e liberdade.

Mantemos, ainda, a constatação de que os ajustes sugeridos melhorarão ainda mais as condições de conforto, melhorando resultados no relacionamento entre usuários e profissionais dos serviços. A melhoria do ambiente emocional aumenta a produtividade e melhora o relacionamento entre colegas de trabalho, 0 que estimula a produção de subjetividades e incrementam a pró-atividade, facilitando ainda mais a satisfação da equipe.

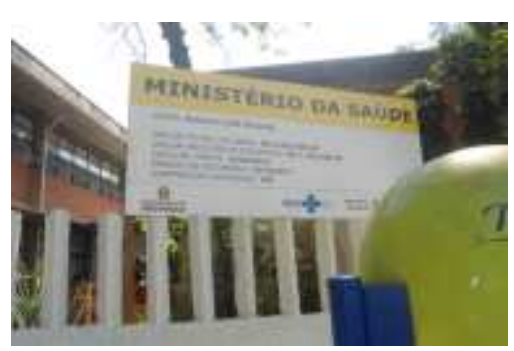

Setembro de 2012

Na pesquisa ficou constatado que a reforma no CSE Prof. Samuel Barnsley Pessoa já demonstra mudanças de comportamento e percepção pelos usuários idosos. A comparação dos resultados coletados na primeira fase com os de agora poderão gerar iniciativas no sentido de ajustar necessidades que tenham sido percebidas após o período mais crítico de obras. No relatório apresentado anteriormente ficou estabelecido que os dados fossem novamente coletados no ano 
de 2012 utilizando o mesmo instrumento, buscando a obtenção de novos aspectos quanto aos resultados práticos da reforma no CSE Butantã.

Fotos 44-46: Modernização dos dispositivos de atendimento antes, durante e após a reforma.

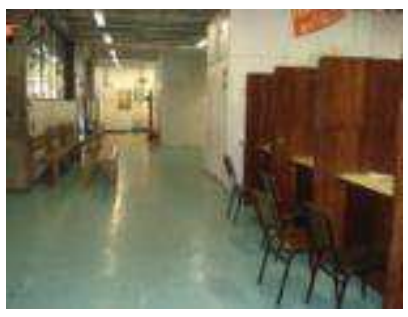

Foto 44: 06-03-2010

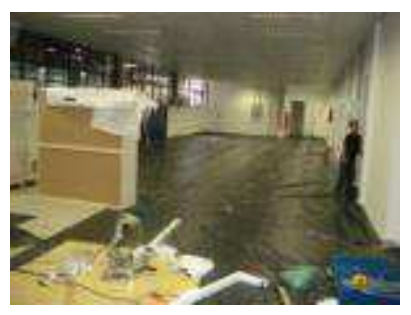

Foto 45: 16-12-2010

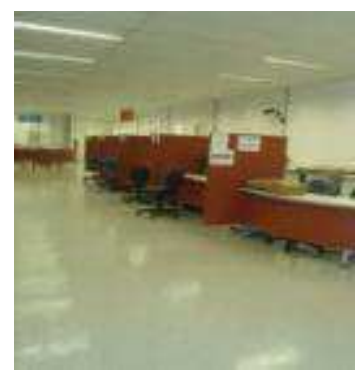

Foto 46: 29-09-2012

Quando se pensa em projetar ambientes para o envelhecimento humano, essa abordagem apresenta-se particularmente pertinente, tendo em vista que esse processo modifica as relações do indivíduo com o seu ambiente. A compreensão dessas novas relações que os indivíduos passam a desenvolver com os seus ambientes à medida que envelhecem é, portanto, de fundamental importância para a tarefa de identificar as necessidades dos idosos em relação ao ambiente construído. Sabe-se que o processo de envelhecimento é um fenômeno bastante complexo e que ocorre de forma multidimensional. Toda e qualquer intervenção que vise a aumentar a qualidade de vida dos idosos deve ter em vista essa complexidade, o que exige, necessariamente, uma visão interdisciplinar. Buscar os atributos do espaço físico e emocional através de projetos bem elaborados, em níveis de complexidade que vão desde peças do mobiliário até cidades planejadas, certamente contribuirá para o aperfeiçoamento da qualidade de vida que almejamos para um envelhecimento saudável, em busca de melhor bem-estar e equilíbrio ambiental.

\section{Agradecimentos}

Agradecemos à equipe do CSE Samuel Barnsley Pessoa, em especial ao Dr. Alexandre Nemes e à Dra. Ana Sílvia Dalmaso, pela oportunidade de realizarmos a pesquisa e pela sua disposição em nos receber com tanta simpatia. 


\section{REFERÊNCIAS}

ASSOCIAÇÃO BRASILEIRA DE NORMAS TÉCNICAS. NBR 9050-2004 Acessibilidade a edificações, mobiliário, espaços e equipamentos urbanos. 2. Ed. Rio de Janeiro: ABNT, 2004.

BESTETTI, M. L. T. Ambiência: o espaço construído como fator de envelhecimento saudável. Congresso Luso-Brasileiro para o Planeamento Urbano, Regional, Integrado e Sustentável. Universidade do Algarve - Faro, Portugal, 06 a 08 de outubro de 2010. Anais... Algarve: Universidade do Algarve, 2010.

BOTTON, A. D. A Arquitetura da Felicidade. Rio de Janeiro: Rocco, 2007.

CACHIONI, M.; FALCÃO, D. V. S.. Velhice e Educação. Possibilidades e benefícios para a qualidade de vida. In: FALCÃO D. V. S.; ARAÚJO L. F. (orgs.). Psicologia do Envelhecimento: relações sociais, bem-estar subjetivo e atuação profissional em contextos diferenciados. Campinas: Alínea, 2009.

BRASIL. Ministério da Saúde, Secretaria de Atenção à Saúde. Núcleo Técnico da Política Nacional de Humanização. Cartilha de Ambiência. 2. Ed, Brasília:

Ministério da Saúde, 2006. Disponível em: www.saude.gov.br/humanizasus. Acesso em: set. 2007.

DIOGO, M. J. D. O Envelhecimento da Pessoa Portadora de Necessidades Especiais. In: DIOGO, M. J. D.; CACHIONI, A. L. Neri, M. (org.). Saúde e Qualidade de Vida na Velhice. 2. Ed.Campinas: Alínea, 2006.

FERREIRA, A. B. H. Verbete Ambiência. Dicionário Aurélio da Língua Portuguesa. São Paulo: Cultura, 2004.

FLECK, M. P. A. (coord.). Versão em Português dos Instrumentos de Avaliação de Qualidade de Vida (WHOQOL). Porto Alegre: UFRGS, Departamento de Psiquiatria e Medicina Legal, 1998. In: http://www.ufrgs.br/Psiq/whoqol.html. Acesso em out/2008.

HALL, E. T. A Dimensão Oculta. São Paulo: Martins Fontes, 2005.

INSTITUTO BRASILEIRO DE GEOGRAFIA E ESTATÍSTICA. Características da População e dos Domicílios: resultados do universo. Rio de Janeiro: IBGE, 2010. Disponível em:

www.ibge.gov.br/home/estatistica/populacao/condicaodevida/indicadoresminimos/sin teseindicsociais2010/SIS_2010.pdf. Acesso em nov. 2012.

MACEDO, D. et al.. O Lugar do Afeto, o Afeto pelo Lugar: O que Dizem os Idosos? Revista Psicologia: Teoria e Pesquisa, Brasília, Vol. 24 n. 4, p. 441-449, Out-Dez de 2008.

MAIA, E. M. C., FERREIRA, C. L.. Envelhecimento e Desafios Adaptativos. In: FALCÃO, D. V. S.; ARAÚJO, L. F. (orgs.). Psicologia do Envelhecimento: relações sociais, bem-estar subjetivo e atuação profissional em contextos diferenciados. Campinas: Alínea, 2009. 
NERI, A. L. (org.), Idosos no Brasil: vivências, desafios e expectativas na terceira idade. São Paulo: FPA/SESCSP, 2007.

OKAMOTO, J. Percepção ambiental e comportamento: visão holística da percepção ambiental na arquitetura e na comunicação. São Paulo: Mackenzie, 2002.

PERRACINI, M. R.; FLÓ, C. M. Funcionalidade e envelhecimento. Rio de Janeiro: Guanabara Koogan, 2009.

RODRIGUES, M. P., ARAÚJO, M. S. S. O fazer em saúde: um novo olhar sobre o processo de trabalho na estratégia Saúde da Família. Natal: UFRN/UFPE, s/d. Disponível em: <http://www.observatorio.nesc.ufrn.br/texto_polo05.pdf>. Acesso em: nov. 2013.

SCHMID, A. L. A Ideia de Conforto: reflexões sobre o ambiente construído. Curitiba: Pacto Ambiental, 2005.

VITTA, A. D. Envelhecimento, capacidade para o trabalho e qualidade de vida no trabalho. In: DIOGO, M. J. D.; NERI, A. L. CACHIONI, M. (org.). Saúde e Qualidade de Vida na Velhice. 2. ed, Campinas: Alínea, 2006. 